\title{
Construções penais e o diálogo com a cidade: a (não) política de implantação de equipamentos penais no meio urbano
}

\author{
Penal institutions and the dialogue with the city: (lack of) policies for \\ implementation of prison facilities in urban areas
}

José Roberto Tenório Filho, Suzann Flávia Cordeiro de Lima

Universidade Federal de Alagoas (UFAL), Núcleo de Estudos de Projetos Especiais (NuPEs), Maceió, AL, Brasil

\section{Resumo}

Este artigo discute a relação espacial entre o espaço penal e a cidade. 0 estudo foi desenvolvido sobre o caso da cidade de Arapiraca (Alagoas), no qual a proximidade entre instalações de unidade penal e instituição de ensino superior criaram um delicado cenário de relações conflituosas. A metodologia do artigo baseia-se em análise documental de registros de doações de terreno, atas de reunião, publicações em Diário Oficial, ofícios expedidos entre a Universidade Federal de Alagoas, a Secretaria de Administração Penitenciária e a Prefeitura de Arapiraca, além de entrevistas semiestruturadas com gestores sobre as decisões para a implantação da unidade penal, além de ressaltar a necessidade de investigações acerca da aparente indiferença do Estado no que tange à integração política e interdisciplinar dos espaços penitenciários nas cidades, levando-se em consideração a complexidade das fronteiras existentes entre uma instituição prisional e o espaço urbano. As relações espaciais do estabelecimento penal como atrativo de expansão da cidade e exercício de poder são evidenciadas de modo que as barreiras físicas das prisões pretendem não somente limitar o acesso e a circulação, como também, na maioria das vezes, produzir um efeito de invisibilidade e de aniquilação da existência de cidadãos presos. Por fim, demonstra-se a relevância de agregar princípios de segurança ao planejamento urbano ou aprimoramento de espaços já construídos, bem como integrar iniciativas espaciais e sociais para enfrentar o desafio coletivo de elevar a segurança nas cidades.

\section{Abstract}

Palavras-chave: Segurança pública. Planejamento urbano. Espaço penal. Políticas públicas.

This paper discusses the spatial relationship between the penal space and the city. The study focused on the case of Arapiraca (city of Alagoas), where the proximity between a penitentiary and a university campus created a delicate scenario of conflicting relationships. The methodology is based on documental analysis and semi-structured interviews with administrators. We highlight the need for investigations about the apparent lack of confrontation by the State regarding the political and interdisciplinary integration of prisons in cities, taking as parameters the complexity of borders that exist between a prison institution and the urban space.

JRTF: Engenheiro Civil, Bacharel, e-mail: jr.roberto@hotmail.com

SFCL: Arquiteta e Urbanista, Doutora em Psicologia, e-mail: suzanncordeiro@hotmail.com 
We show spatial relationships between having the prison as a sign of the city's expansion and the exercise of power, where the physical boundaries of prisons are intended to promote an invisibility and annihilation effect toward the inmates. In the case of Arapiraca, the proximity between the prison and a University building has created a delicate and complex scenario of conflicting relationships. We demonstrate the importance of aggregating principles of security to urban planning and working to improve existing spaces. In addition, it is important to think about integrating spatial and social initiatives to stand up to the challenge of enhancing the urban security.

Keywords: Public safety. Urban planning. Penal space. Public policy.

\section{Introdução}

Desde a Idade Média, a exclusão das pessoas que não se enquadram às regras sociais é utilizada como punição. As Invasões Bárbaras e a consequente queda do Império Romano agravaram a insegurança nas cidades e a terra passou a pertencer àqueles que apresentavam condições de guerra e de defesa, os quais defendiam e recebiam a produção em troca de segurança. Aos que não se adaptaram a tais regras relegou-se a expulsão das cidades; por viverem fora do perímetro social, que se apresentava cercado por muralhas, esses cidadãos estavam permanentemente vigiados e protegidos.

A partir do século XVIII, as ideias de sociedade, Estado e cidade alimentam uma reflexão sobre a arquitetura como uma estratégia espacial para a atividade política. 0 modelo da cidade contempla a delimitação de um lugar territorial, privilegiado em um sistema de regulação da conduta geral dos indivíduos, sendo que o Estado se solidifica nessa função organizativa das relações sociais e econômicas (Cordeiro, 2013). Para o bom funcionamento da cidade e do Estado, uma racionalidade policial se instala na expectativa de criar um sistema de regulação da conduta geral dos indivíduos (Foucault, 2012).

No século XXI, o espaço urbano ainda é considerado o lugar das interações e diferenças sociais, em que a segregação social se revela nas formas de ocupação do solo urbano, marcando fronteiras (in)visíveis, demarcadas por espaços estigmatizados e, supostamente, isolados do restante da cidade. Essas formas de demarcação geram vínculos de hostilidade que passam a compor um cenário de nítidas divergências.

Assim, a produção dos espaços nas cidades ocorre de forma dinâmica e com alto poder polarizador, criando, a cada momento, configurações espaciais bastante peculiares. Na contemporaneidade, a cidade ultrapassa a configuração do passado, apresentando maior heterogeneidade e funcionalidade, maior "escala humana" (Montaner \& Muxí, 2013), contudo entende-se que o diálogo entre planejamento urbano e gestão precisa ser direcionado, com o intuito de melhorar a qualidade de vida dos cidadãos, implicando uma maior compreensão e ampliação do conceito de desenvolvimento urbano.

Nesse sentido, para se compreender a cidade e seus espaços em movimento deve-se ter como pano de fundo a sociedade urbana em constante processo de transformação. A urbe tem a dimensão do humano, refletindo e reproduzindo-se através do movimento da vida, de um modo de vida, de um tempo específico (Carlos, 1994).

A Constituição Brasileira de 1988 determina que é competência dos municípios legislar sobre seus territórios (uso e ocupação do solo) devendo a propriedade e a cidade atenderem suas funções sociais; embora a função social da propriedade e da cidade tenham sido traduzidas na política urbana quanto ao direito à moradia, principalmente a de interesse social, que ganha notoriedade no Estatuto da Cidade e na MP 2220/02 (Cordeiro \& Souza, 2004).

O Estatuto da Cidade propõe a elaboração de instrumentos pelos municípios para que eles garantam o pleno desenvolvimento das funções sociais da cidade em seus Planos Diretores, instrumento legal de política urbana. No entanto, os principais focos dos planos diretores são a infraestrutura e a promoção da habitação de interesse social e não apontam questões relativas à segurança pública. Alguns dos mecanismos de exclusão social operam no Direito Penal, que focaliza tanto a exclusão social do indivíduo condenado pelo sistema de justiça criminal como 
o isolamento dos estabelecimentos prisionais nas cidades que os abrigam.

A política criminal e penitenciária, através do Código Penal Brasileiro (decreto-lei n. 2.848, de 7 de dezembro, Brasil, 1940) e da Lei de Execução Penal (lei n. 7.210, de 11 de julho, Brasil, 1984), define a pena de reclusão como meio para ressocializar e punir o condenado. Dados mostram que esse comumente já estaria excluído da sociedade, antes mesmo do recorte penal, pelo perfil de baixa escolaridade, cor negra, sem trabalho e idade entre 18 e 34 anos da maioria (73\%) (Figura 1).

Considerando que - embora não concordemos com o termo - "ressocialização", para melhor entendimento, implica, necessariamente, inclusão social, porquanto passemos a utilizar esse e não aquele.

A exclusão social pela falta de condições econômicas, pela falta de moradia e pela falta de educação é institucionalizada pelos espaços penais, expulsando da cidade e isolando esses excluídos num estabelecimento fechado no qual a sociedade exige muros altos para que o confinamento seja ainda maior do que o detectável a olhos nus.

Ao analisar os espaços destinados à população carcerária, faz-se importante compreender o seu direito à reinserção na sociedade através da garantia das funções sociais nos espaços de segurança, o que parece ser objetivamente contraditório, quando se exclui do perímetro urbano os estabelecimentos penais, se contraposto, da mesma forma, a permissão planejada de uso específicos para fins de segurança, para implantação desses estabelecimentos, permitindo-se uma localização inserida no perímetro urbano que seja condizente com as necessidades e providências de segurança dos mesmos.

\section{PERFIL \\ - Maior parte população carcerária do Brasil é formada por jovens \\ Faixa etária \\ 18 a 24 anos \\ 19 a 29 anos \\ 30 a 34 anos \\ 35 a 45 anos \\ 46 a 60 anos \\ 61 a 70 anos \\ 71 anos ou mais \\ Raça, cor ou etnia

\begin{tabular}{l}
$31 \%$ \\
$25 \%$ \\
$19 \%$ \\
$17 \%$ \\
$7 \%$ \\
\hline $1 \%$ \\
\hline $0 \%$
\end{tabular} \\ Sistema prisional $67 \%$



\section{Escolaridade}

Ensino fundamental incompleto

Ensino fundamental completo

Ensino médio incompleto

Alfabetizado (sem recursos regulares)

Ensino médio completo

Analfabeto

Ensino superior completo

Figura 1 - Perfil da população carcerária brasileira Fonte: INFOPEN/CONECTAS, 2017. 
A falta de coerência entre as demais políticas públicas e a política de segurança pública dificulta o processo de ações em prol da diminuição da violência urbana. Uma vez que não há consenso acerca da real política a ser adotada, os espaços de segurança pública ficam desassistidos, como se fossem unidades autônomas esquecidas ou negadas nos municípios.

Nesse sentido, o texto parte de uma breve explicitação da centralidade da instituição prisional na cidade, não obstante o não enfrentamento dessa centralidade pelo planejamento urbano, respaldado pela exclusão desse espaço imposta pela LEP, art. 90. A penitenciária de homens será construída, em local afastado do centro urbano, à distância que não restrinja a visitação (Brasil, 1984).

Para isso, descreve-se o caso do Estabelecimento Prisional de Arapiraca - Alagoas, construído em 2002 e implantado fora do perímetro urbano, mas que num curto espaço de tempo foi abraçado pelo projeto de um campus da Universidade Federal de Alagoas (UFAL), e, posteriormente, por vários bairros residenciais, ocasionando, por vezes, problemas de segurança na sua circunvizinhança.

\section{O espaço público e o desenho urbano como prevenção da violência}

A importância do desenho urbano para a prevenção do crime surge na década de 1970 com as teorias de Oscar Newman sobre o espaço defensável (defensible space, no original), seguido pelo conceito de Prevenção do Crime através de Desenho Ambiental (Crime Prevention through Environmental Design), até a prevenção situacional, nos anos 1990, e a criminologia ambiental (Gartner, 2008, p. 61).

De acordo com Soares (2006, p. 92), a diminuição da criminalidade "requer intervenção social preventiva bem coordenada, territorialmente circunscrita e sintonizada com a multidimensionalidade dos problemas envolvidos". 0 problema da violência urbana é complexo e o trabalho com segurança pública envolve uma série de setores, bem como de profissionais de diversas áreas que devem trabalhar em conjunto.

Desse modo, a interdisciplinaridade deve ser capaz de produzir diretrizes gerais, porém os municípios precisam ter ciência da sua responsabilidade de planejar e executar políticas de segurança pública, tornando-se cogestor/copartícipe da segurança pública, primordialmente no âmbito da prevenção.

Para que o município tenha condições de implantar políticas locais de prevenção da violência faz-se imprescindível realizar um processo composto por algumas etapas: 1. realização de um diagnóstico preciso sobre a situação da violência e da criminalidade, bem como sobre os programas e outras potenciais soluções em andamento; 2. a elaboração das estratégias de intervenção, ou seja, a formulação de um plano de ações focado nos problemas priorizados a partir do diagnóstico; 3. a execução do plano de ações; 4. monitoramento de todo o processo e a avaliação do impacto e dos resultados alcançados pela política/programa/projeto. É válido ressaltar que, embora a ação seja focada, ela deve ser pensada dentro de um planejamento territorial que considere as especificidades de cada região.

A ausência de planejamento urbano relativa aos equipamentos de segurança pública coaduna com os altos índices de violência criminal e com a ausência de dados de espacialização dessa violência capazes de contribuir nas estratégias de localização e implantação dos equipamentos de segurança ${ }^{1}$ na cidade.

Tal como narra Gartner (2008), o desenho urbano pode criar condições para a segurança dos espaços da cidade, nas quais o espaço pode ser ou não favorável para a prática de um crime.

Nesse quesito, arquitetos e urbanistas agem no planejamento dos espaços urbanos e no desenvolvimento de projetos de equipamentos de segurança e devem compreender a questão da segurança no processo de produção desses espaços, onde

[...] todas as estratégias devem incorporar processos multidisciplinares e interinstitucionais, cujos atores incluem as forças da lei, urbanistas e arquitetos, autoridades municipais, membros de conselhos locais e de comunidades, educadores e demais organismos e pessoas que trabalham no desenho de espaços públicos (Gartner, 2008, p. 66).

\footnotetext{
${ }^{1}$ Quando se fala em equipamentos de segurança considera-se tanto as instituições distribuídas na cidade, que têm como objetivo atender a população e prevenir a prática de crimes, tais como as delegacias, batalhões de polícia, postos policiais etc., como também as instituições voltadas para a ressocialização dos que infringiram as leis, como é o caso das penitenciárias, unidades socioeducativas, casas de albergados, hospital de custódia, centros psiquiátricos etc. (Cordeiro, 2010).
} 
Na tentativa de aumentar a segurança pública, há uma tendência de se fechar os espaços públicos, o que provoca o abandono, o medo e a insegurança. Nesse âmbito, Gartner (2008) defende aa ineficácia de se adotarem apenas políticas preventivas e repressivas, na verdade, elas devem estar atreladas às sociais, econômicas e culturais, além do desenvolvimento de uma política dirigida aos espaços públicos.

Considerando-se a realidade do Estado de Alagoas, por exemplo, dados do Núcleo de Estatística e Análise Criminal (NEAC, 2015), revelam que nos últimos quatro anos - 2013, 2014, 2015, 2016 - a maior parte dos crimes violentos letais e intencionais do Estado ocorreram em vias ou locais públicos $(60,97 \%$ em 2013; 57,6\% em 2014; 53,2\% em 2015 e 55,4\% no primeiro semestre de 2016).

Geralmente, a prevenção da violência se divide em três categorias: (1) prevenção primária - tenta mudar condições gerais que influenciam basicamente a população (pessoas, lugares e situações que favoreçam a violência); (2) secundária - tem por foco interventivo indivíduos, grupos ou condições sociais que podem desencadear e participar de ações violentas e criminosas, ou seja, grupos de risco previamente identificados; e (3) terciária desenvolve ações para evitar ocorrência de delitos, trabalhando primordialmente com pessoas que já os cometeram. As categorias mais comuns de prevenção não fazem referência aos lugares em que ocorrem os crimes e a importância desses apontamentos para uma prevenção bem-sucedida.

Desse modo, as ações para modificar tal realidade devem ser feitas de maneira integrada e contínua.

O levantamento das dinâmicas espaciais de delitos é imprescindível antes de qualquer implementação de estratégia de prevenção. Somente após análise rígida georreferenciada é possível avaliar o impacto que uma intervenção que inclua o desenho urbano espacial possa ter sobre os delitos em questão (Gartner, 2008, p.63).

Por outro lado, as legislações voltadas para a segurança pública, apesar de pregarem uma prática multidisciplinar, ao descreverem suas estratégias de ação também não consideram a integração com as demais políticas e o planejamento dos espaços públicos. Assim, os aspectos de segurança mais uma vez são esquecidos.
A desarmonia entre as políticas públicas municipais e a política pública penitenciária, especificamente, dificulta o processo de ações em prol da diminuição da violência urbana, a falta de consenso em relação à política pública a ser implantada resulta na adoção da ausência de previsão desses espaços, que se configuram como não política urbana para os espaços penitenciários, como se os mesmos fossem unidades autônomas aos municípios. Assim, o espaço penitenciário continua à espera da definição quanto a sua função social para pautar a implementação das demais ações de ressocialização que abriga.

\section{Impactos do estabelecimento penal na cidade}

A partir do ano 2000, a exclusividade dos estados na formulação e execução de políticas de segurança pública passou a ser questionada (Ricardo \& Caruso, 2007), ganhando força a ideia de que o município, como unidade federativa mais próxima do cidadão, pode e deve atuar na gestão local dos problemas de violência e criminalidade, ou seja, o poder local pode e deve pensar soluções para sua própria realidade.

A lei n. 10.257, de julho de 2001 (Estatuto da Cidade), define em seu art. $2^{\circ}$ que

A política urbana tem por objetivo ordenar o pleno desenvolvimento das funções sociais da cidade e da propriedade urbana, mediante as seguintes diretrizes gerais:[...]I - garantia do direito a cidades sustentáveis, entendido como o direito à terra urbana, à moradia, ao saneamento ambiental, à infraestrutura urbana, ao transporte e aos serviços públicos, ao trabalho e ao lazer, para as presentes e futuras gerações; [...] V - oferta de equipamentos urbanos e comunitários, transporte e serviços públicos adequados aos interesses e necessidades da população e às características locais; VI - ordenação e controle do uso do solo, de forma a evitar: [...] b) a proximidade de usos incompatíveis ou inconvenientes; c) o parcelamento do solo, a edificação ou o uso excessivos ou inadequados em relação à infraestrutura urbana; d) a instalação de empreendimentos ou atividades que possam funcionar como polos geradores de tráfego, sem a previsão da infraestrutura correspondente (Brasil, 2001). 
Aproveitando os 10 anos do Estatuto da Cidade, com a previsão de revisão dos Planos Diretores, que ocorreria em 2011, o Conselho Nacional de Política Criminal e Penitenciaria (CNPCP) do Ministério da Justiça buscou junto ao Ministério das Cidades e à Associação Brasileira dos Municípios (ABM) iniciar discussões que permitissem a reflexão sobre a implantação dos estabelecimentos penais, porém não obteve sucesso. A sugestão de inserção nas conferências municipais também não logrou êxito, permanecendo fora das discussões questões de enfrentamento dos impactos relacionados à implantação desse tipo de equipamento.

Enquanto a questão da ilegalidade do solo urbano parece estar sendo tratada sob a óptica do direito de propriedade, outras questões referentes à função social dos espaços de segurança pública nas cidades não têm sido ponto de pauta nas políticas urbanas, nem nas discussões de direito urbanístico, apesar de se apontar a insegurança como um dos principais problemas das cidades, atualmente.

A capacidade atrativa do estabelecimento penal o coloca na categoria de Polo Gerador de Tráfego (PGT), haja vista a implantação de um estabelecimento penal em determinada localidade atrair fluxos de funcionários - para atendimento dos indivíduos presos - , de familiares - em dias específicos de visita aos presos - de veículos de transporte coletivo e/ou privados, veículos de carga e descarga de mercadorias ou produtos para a subsistência do estabelecimento, de veículos que levam e trazem os próprios presos etc., os quais necessitam de vias pavimentadas ou, ao menos, de fácil acesso dos usuários, com pontos de embarque e desembarque de transporte coletivo, com dimensões adequadas para circulação de veículos de pequeno, médio e grande portes.

0 deslocamento de pessoas resultante da implantação de um estabelecimento penal acontece em função da ocupação do solo para diferentes usos e pode ser motivado por trabalho, negócios, educação, saúde e lazer. Dessa forma, iniciativas que visam garantir ao cidadão o seu direito de ir e vir, de maneira segura e preservando a sua qualidade de vida, são uma exigência.

\section{Contextualização da violência em Alagoas}

O Estado de Alagoas, notoriamente, carece de muitos recursos de capital humano especializado que comunguem de ideias inovadoras e consoantes com o restante do país para que possa almejar uma cidadania, senão plena, ao menos considerável justa. O precário trinômio, Educação/Emprego-renda/Saúde está refletido nos baixos indicadores sociais. Embora o Índice de Desenvolvimento Humano (IDH) tenha passado de 0,548 (em 1991) para 0,649 (em 2000), em 2005 chegou a 0,677 , mas apresentou queda para 0,631 em 2014; e no índice Gini (que mede a desigualdade da distribuição de renda) apresentou um aumento de 0,63 (em 1991) para 0,69 (em 2000), no entanto em 2009 chegou a 0,572 e, em 2013, 0,456 , representando a redução da desigualdade de renda. Esses dados demonstram que Alagoas não acompanhou a evolução do país, apresentando, ainda, os piores indicadores dentre os estados. Uma consequência nítida dessa condição é o aumento da violência urbana.

Impulsionado pelas demandas da cidadania na área da Justiça e da Defesa Social, o Estado de Alagoas formulou o Plano Estadual de Segurança Pública (PESP/AL), em sincronia com o projeto adotado pela Secretaria Nacional de Segurança Pública (SENASP), cujo objetivo era planejar ações de repressão ao crime, a partir do que era considerado como a realidade alagoana (SEDS, 2009).

A política de segurança pública alagoana, além de trabalhar primordialmente sob o viés repressivo, como se pode constatar por meio das pesquisas referentes aos equipamentos de Segurança Pública de cunho preventivo-assistencial (apoio a vítimas, apoio a egressos, Procon etc.), não considera a simbologia dos atos violentos, parametrizando-se apenas em seus aspectos objetivos, palpáveis, sem se interessar pelo desvelamento das causas do ato criminoso.

Em Alagoas, percebemos que, na maioria das vezes, a Política Estadual de Segurança Pública assume um caráter emergencial, quando as autoridades conseguem arrefecer a fúria da mídia e a pressão popular param de investir em ações efetivas. Não há planejamento a longo prazo, nem projetos e programas que considerem a dimensão cultural dos sujeitos envolvidos em atos violentos. A militarização da segurança e a falta de diálogos efetivos com a sociedade caracterizam a realidade alagoana.

No Mapa da Violência 2016, Alagoas se apresenta como o estado mais violento do país em número de homicídios, respeitada a proporcionalidade, segundo taxas de homicídio (Waiselfiz, 2016), e Arapiraca é apresentado como $18^{\circ}$ município com maior taxa de 
homicídio por 100 mil habitantes (188 mortes). 0 autor afirma que estados que, no início da década, ostentavam níveis moderados ou baixos para contexto nacional, apresentavam crescimento severo, como Alagoas, Pará ou Bahia, os quais de $11^{\circ}, 21^{\circ}$ e $23^{\circ}$ lugares passam para o $1^{\circ}$, o $3^{\circ}$ e o $7^{\circ}$ posto nacional, com crescimento que triplica ou quadruplica quantitativos em 10 anos (2002-2012).

No tocante ao cenário penal, em âmbito nacional, Alagoas ocupa a 20 a colocação no ranking de déficit de vagas em estabelecimentos penitenciários no Brasil, correspondendo a 1,06\% do total. De acordo com dados da Secretaria de Estado da Defesa Social (SEDS-AL), o Estado apresenta uma população carcerária de 3.602 detentos, dos quais cerca de $22 \%$ estão lotados em unidade do agreste do Estado, e capacidade de 2.632 vagas, totalizando um déficit de aproximadamente $37 \%$.

\section{Análise da implantação de equipamento de segurança: estudo de caso no município de Arapiraca}

Na estrutura urbana brasileira, o papel que as cidades médias assumem é de extrema relevância, uma vez que são polarizadoras e organizadoras de bens e serviços que antes se encontravam restritos às grandes metrópoles ou vinculados às capitais estaduais. 0 quadro extremamente complexo que já se cristalizou nos espaços urbanos das metrópoles mundiais são geradores de crises sociais que tornam ainda mais caótico o espaço metropolitano, conforme aponta Souza (2009).

Localizada na região agreste do estado brasileiro de Alagoas (Figura 2), Arapiraca se apresenta como principal cidade do interior do Estado, contando com aproximadamente 220 mil habitantes (IBGE, 2014), apresentando, segundo o mesmo órgão, a terceira maior evolução de Produto Interno Bruto (PIB) na Região Nordeste. De posse da segunda maior economia do Estado, a cidade de Arapiraca foi apontada em 2009 como o $10^{\circ}$ município mais dinâmico do Brasil, pela Agência de Estudos e Pesquisas Florenzano Market de São Paulo, e uma das 22 metrópoles do futuro (Coutinho, 2010).

Como o mais novo conglomerado humano de Alagoas, Arapiraca apresenta uma evolução nos seus índices populacionais, diga-se incremento, nos últimos 30 anos (entre 1970 e 2000) da ordem de aproximadamente $50 \%$, tendo atingido $214 \mathrm{mil}$ habitantes em 2010, apresentando estimativa de 229.329 habitantes em 2014 e IDHM de 0,649 (IBGE, 2014). Igualmente, o crescimento da população urbana totalizou nesse mesmo período, 57\%, implicando uma taxa de urbanização de 81,71\% (ONU, 2000).

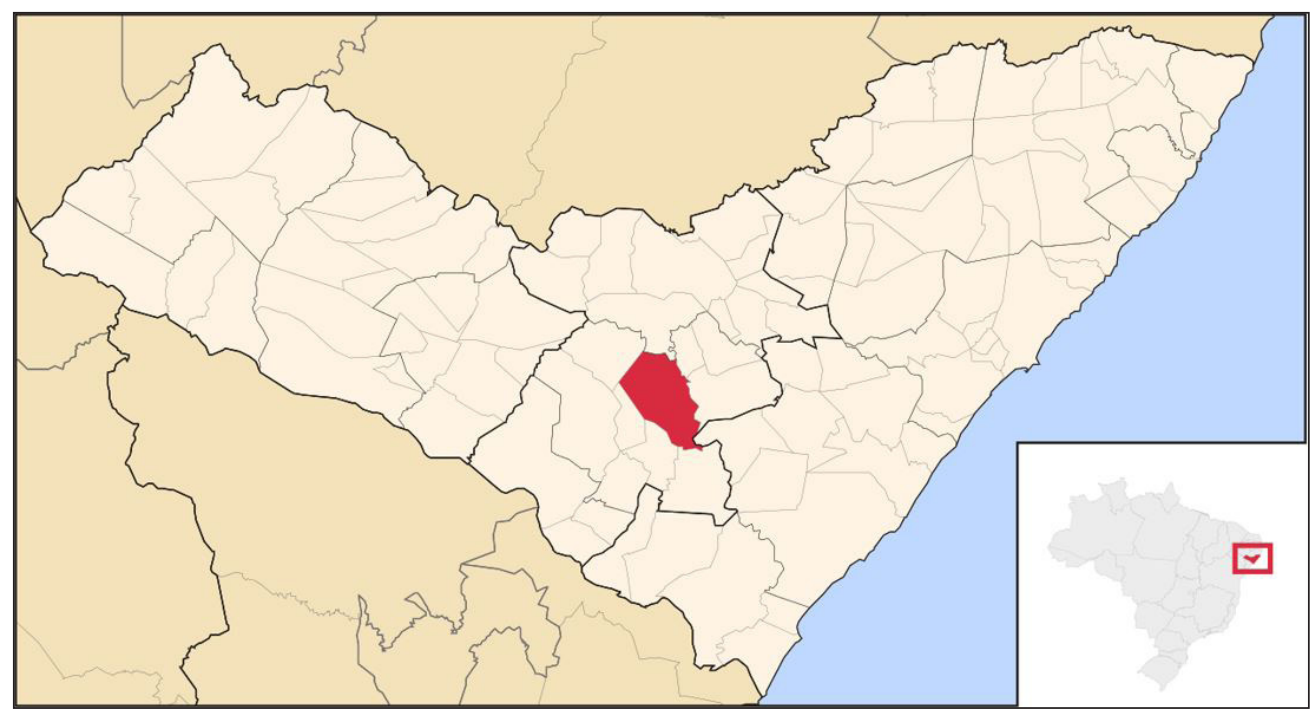

Figura 2 - Localização de Arapiraca no Estado de Alagoas Fonte: Wikipedia. 


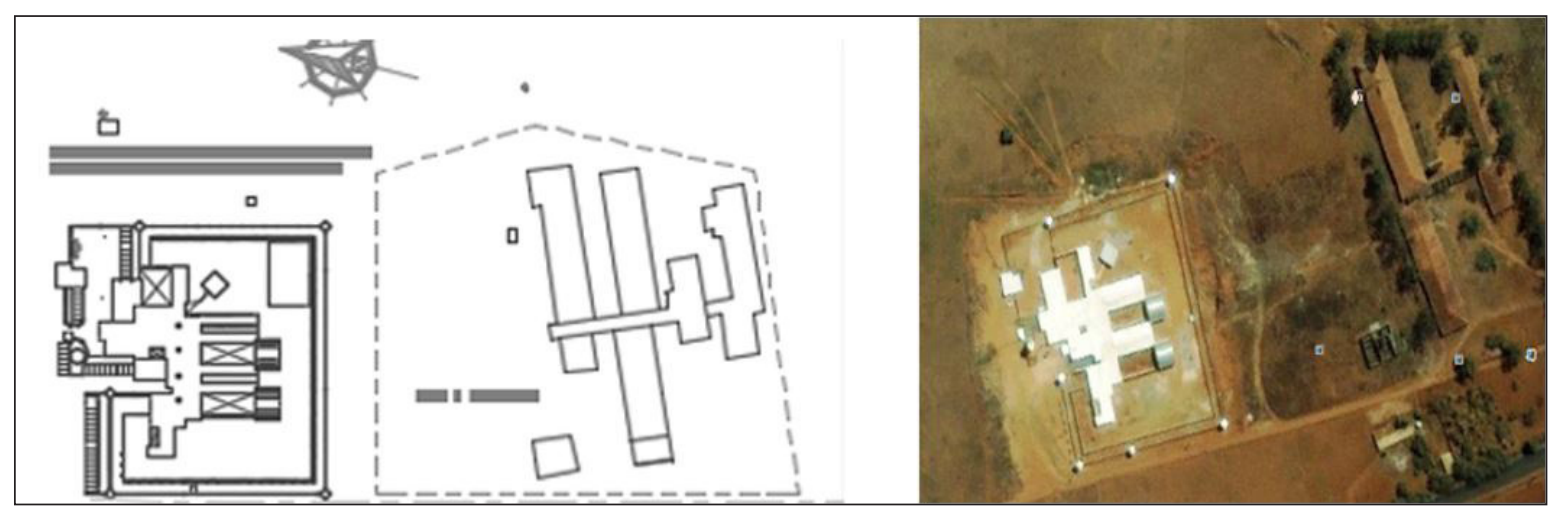

Figura 3 - Configuração espacial da unidade (espaço projetado, à esquerda, vs. espaço construído, à direita) Fontes: arquivo autores/Google Earth ${ }^{\circledR}$.

O processo de implantação e operação da unidade penal

No quesito Segurança Pública, Arapiraca ocupa, atualmente, a $18^{\underline{a}}$ colocação no ranking das maiores taxas médias de homicídios dentre os municípios brasileiros com mais de 10 mil habitantes. Dentre os municípios alagoanos, no ranking nacional, fica atrás de Murici ( $2^{\circ}$ lugar), Satuba ( $3^{\circ}$ lugar), Pilar (6음 lugar), Marechal Deodoro (11ํlugar) e Rio Largo (15으 lugar) (Waiselfisz, 2015).

Com uma malha de equipamentos de segurança concentrada na capital, foi projetado em 2001 e inaugurado em 2003 o presídio de segurança média Desembargador Luiz de Oliveira Souza, na cidade de Arapiraca que, em razão da importância que assume no interior do Estado e do crescimento apresentado ao longo dos últimos anos, passou a albergar a primeira unidade prisional fora da capital, como unidade regional de cumprimento de pena.

Com essa providência, pretendia-se manter os detentos advindos do interior mais próximos de suas raízes. Além disso, permitia-se que as sociedades locais tivessem maior dimensão do problema da criminalidade, despertando em seu íntimo a consciência de sua responsabilidade na recuperação daqueles que se encontravam segregados, mas que voltariam, em breve, a desfrutar do convívio social.

Projetado para funcionar como uma unidade de ressocialização em regime semiaberto ${ }^{2}$, com um total de

\footnotetext{
${ }^{2}$ De acordo com informações da autora deste artigo, e arquiteta responsável pelo projeto, em 2001-2003, e entrevista realizada em 15/1//2017 com o Secretário de Justiça da época, atualmente Desembargador Tutmés Airan.
}

128 vagas, a unidade passou (ainda em seus primeiros anos de funcionamento) por mudanças consideráveis, incluindo a forma de adequação do espaço à uma utilização não planejada - passando a funcionar como estabelecimento para presos provisórios - até sua eventual desativação, em novembro de 2013.

Ainda durante a fase de construção, a implantação do projeto foi alterada com uma inversão na orientação do terreno (Figura 3) e no processo de ocupação abrigou detentos em regime provisório sem que houvesse atenção às diferenças inerentes ao funcionamento e programa de necessidades dessas duas categorias de estabelecimento penal, com distintos perfis de usuário.

A utilização do espaço para objetivo distinto do planejado trouxe, de imediato, o problema da superlotação, posto que a funcionalidade do estabelecimento sofreu alterações estruturantes e, em decorrência da alteração do uso, passaram a ser transferidos para essa unidade aqueles presos que estavam abrigados em delegacias, nas comarcas próximas à cidade. Já em seus primeiros anos de funcionamento, a unidade apresentava um excesso populacional de 116 detentos.

Para lidar com a situação, sempre de forma emergencial, foram autorizadas pela administração penitenciária construções de novos espaços (Figura 4) para acomodação desse contingente populacional em excesso, adicionando-se celas improvisadas e transformando espaços como os módulos de sala de aula e trabalho em áreas de convivência coletiva ou isolamento.

Com essas intervenções não planejadas, os espaços que antes eram destinados às atividades de ressocialização do detento em regime semiaberto (educação, trabalho, encontros religiosos, quartos de visita íntima) foram transformados em espaços 


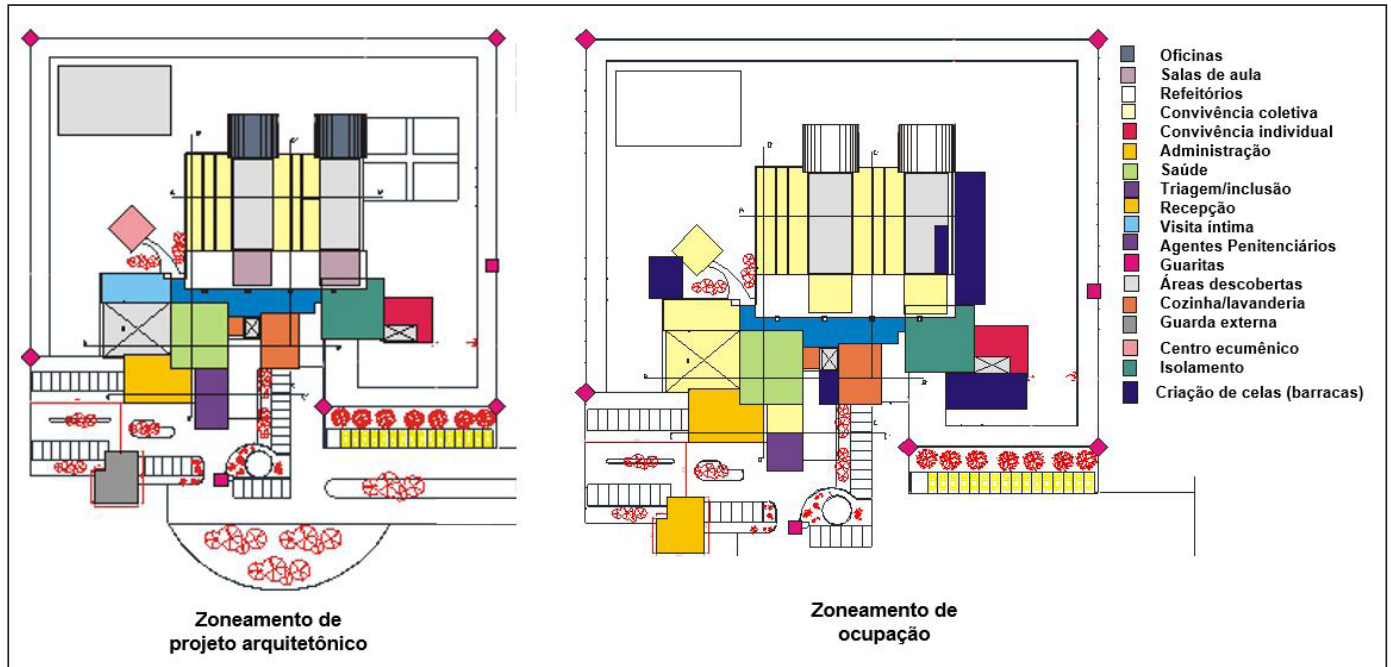

Figura 4 - Alterações pós-ocupação no projeto original da unidade

Fonte: autores.

de cela e abrigo. As alterações, no entanto, não foram suficientes para resolver o problema da superlotação, conforme mostram dados da Superintendência Geral de Administração Penitenciária (SGAP) nos três últimos anos de funcionamento da unidade (Figura 5).

\section{A chegada do campus universitário e o conflito entre as instituições}

Dois anos após a instalação do presídio (setembro de 2006) foi implantado no município um campus da Universidade Federal de Alagoas. A implantação do campus caracterizou a primeira etapa do processo de interiorização da Universidade e sua presença no interior do Estado veio possibilitar o acesso ao ensino superior público, gratuito e de qualidade a uma enorme parcela de estudantes com baixa ou nula capacidade de deslocamento ou transferência para a capital Maceió, onde se localiza o campus sede da instituição.

Como contrapartida ao processo de interiorização, a Prefeitura Municipal de Arapiraca doou, através da lei municipal n. 2.372, de setembro de 2004, área de terra de propriedade do município nas imediações do já instalado e em funcionamento Presídio Desembargador Luiz de Oliveira Souza. A medida, vista como um avanço na interiorização do ensino superior do Estado, trouxe consigo não só o desenvolvimento, mas uma alteração altamente significativa na dinâmica espacial e urbana na região, uma vez que o processo se deu sem respeitar os limites de segurança da

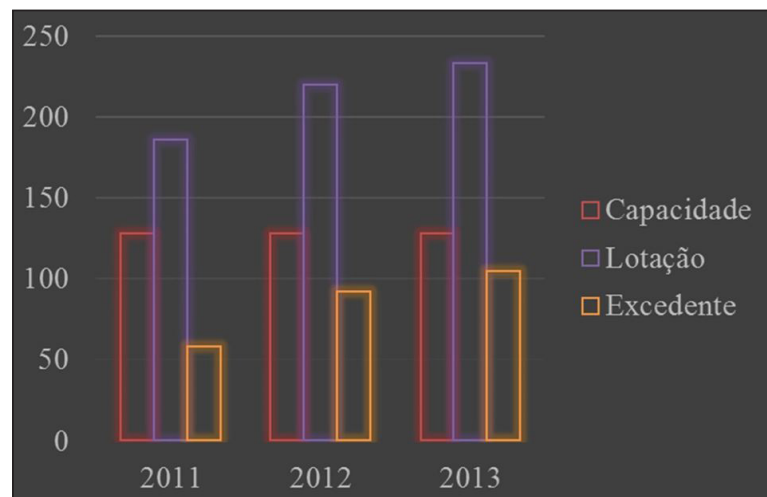

Figura 5 - Evolução da população carcerária do estabelecimento entre 2011 e 2013 Fonte: autores.

unidade prisional, que deveriam ter sido definidos pela administração municipal.

Para aprovação da implantação do novo campus, a classificação da região passou de Zona Rural para Zona de Expansão, no ano de 2005, por meio de alteração no Plano Diretor do Município de Arapiraca. A instalação do campus, que ao longo dos anos expandiu significativamente em direção à área ocupada pelo presídio (Figuras 6 e 7), inviabilizou a existência de uma via perimetral de segurança em torno da unidade e, aliada a uma política municipal que passou a induzir uma grande expansão urbana na região, transformou o que antes era um espaço rural em uma zona urbana com estímulo ao adensamento habitacional (Figura 8).

Todo esse novo contexto urbano territorial em que a unidade passou a estar inserida trouxe consigo 


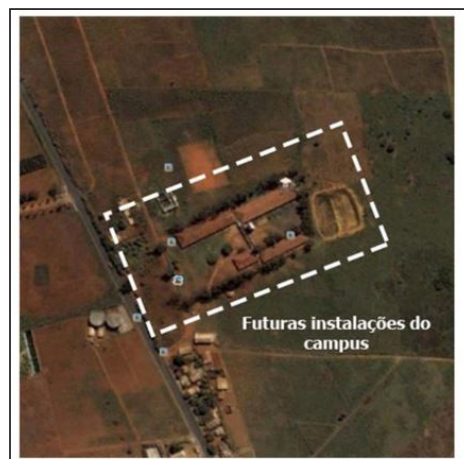

(a)

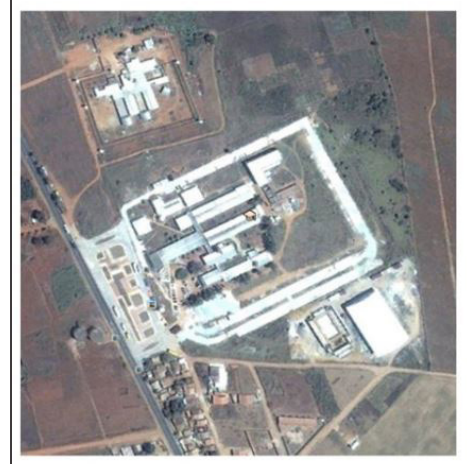

(d)

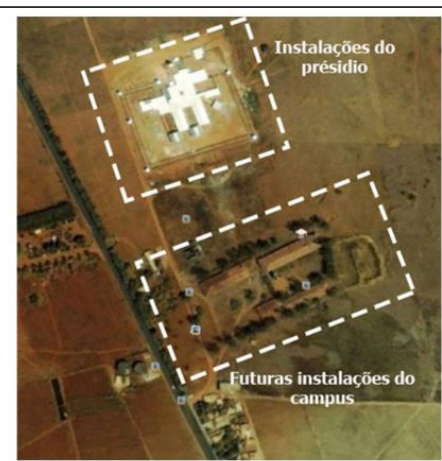

(b)

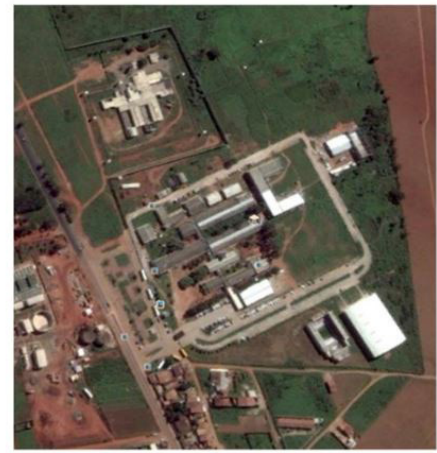

(e)

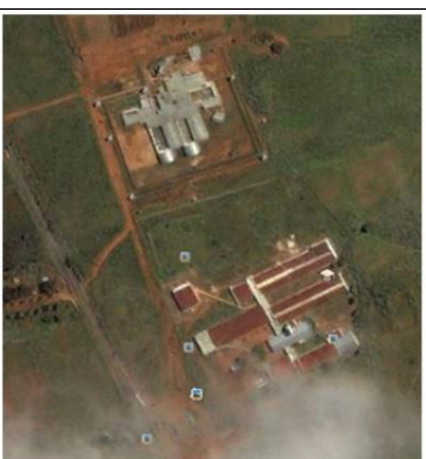

(c)



(f)

Figura 6 - Expansão do campus universitário. (a) 2001 - local antes da implantação do presídio; (b) 2004 - presídio em funcionamento; (c) 2008 campus universitário instalado e em funcionamento; (d) 2011 - expansão do campus; (e) 2012 - construção de novo muro cercando o perímetro do presídio; (f) 2016 - presídio já desativado e incorporado à Universidade Fonte: Google Earth ${ }^{\circledR}$.

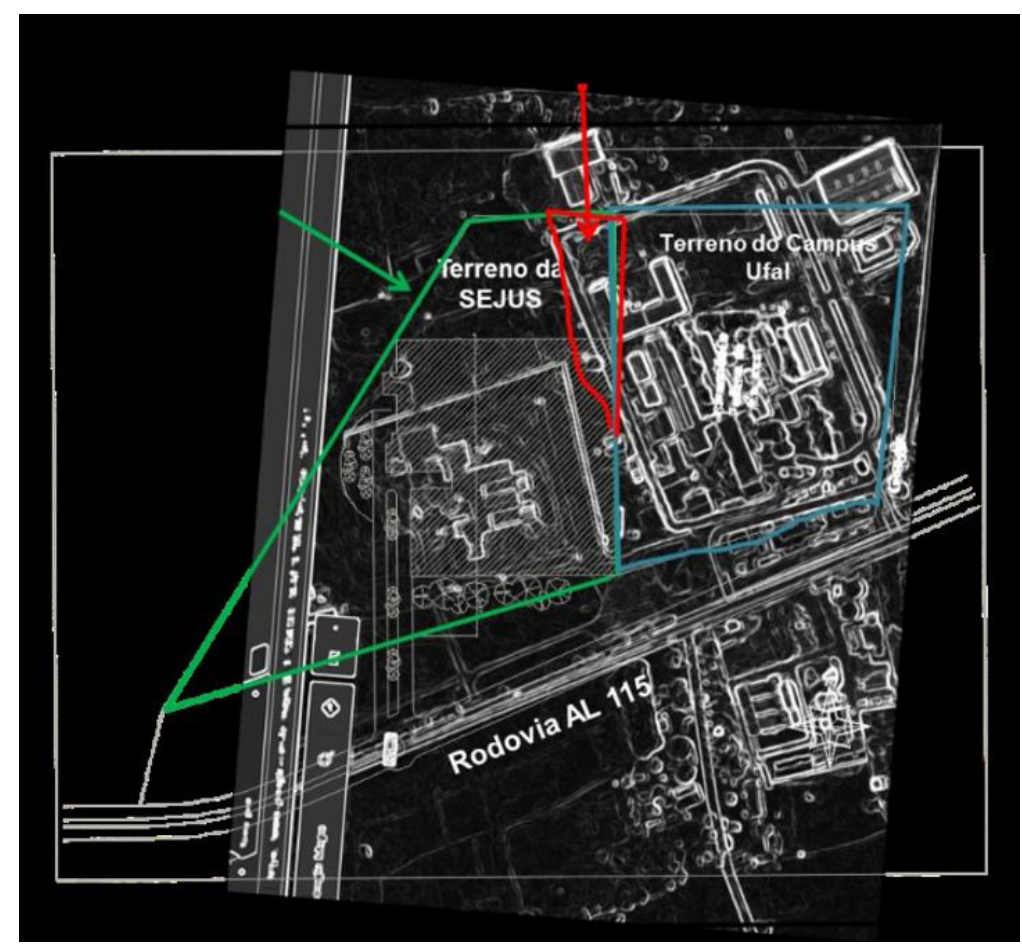

Figura 7 - Zona de conflito espacial entre as instituições Fonte: autores. 


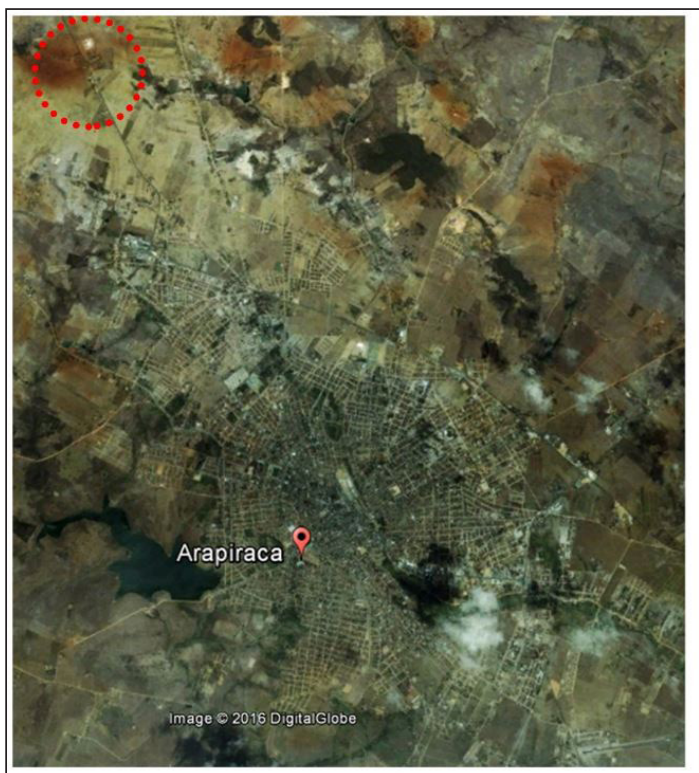

(a)

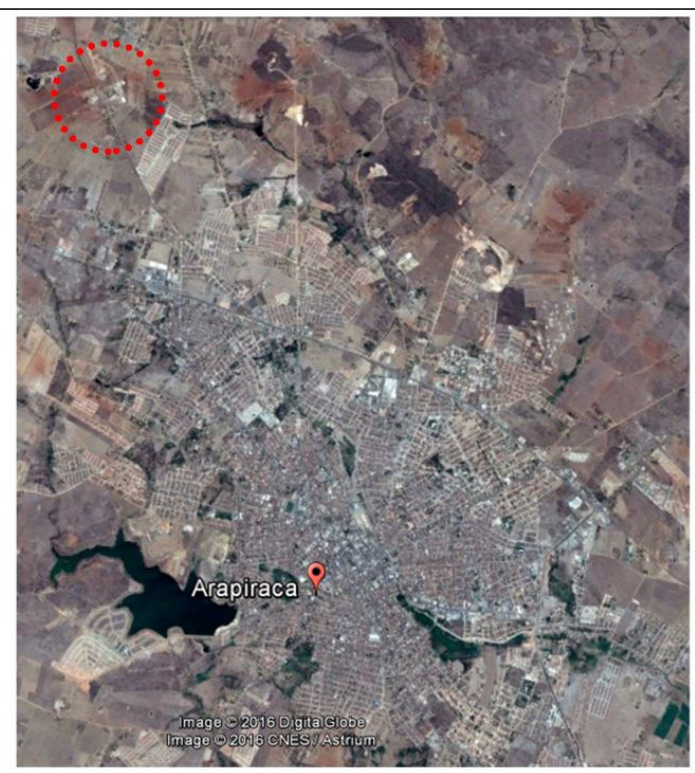

(b)

Figura 8 - Evolução urbana da área de estudo e da cidade, (a) 2001; (b) 2016 Fonte: Google Earth ${ }^{\otimes}$.

um expressivo conflito entre o estabelecimento penitenciário e o espaço circunvizinho externo, conforme linha documental do tempo, apresentada na Figura 9. Com isso, todo e qualquer evento envolvendo rebeliões e/ou tentativas de fuga no presídio adquiriu maiores proporções porque a partir desse momento passou a atingir de maneira direta a população em seu entorno, conforme demonstram os ofícios e documentos consultados (Quadro 1).

No Estado com a maior taxa de homicídios do País, Alagoas, a violência invadiu até os muros da principal universidade pública. A UFAL (Universidade Federal de Alagoas) está sem aulas desde abril, quando mais de 2.000 alunos do campus de Arapiraca, a 137 quilômetros da capital Maceió, foram surpreendidos por tiros durante uma fuga do presídio vizinho (Bibiano, 2012).

Situações dessa natureza, além de sequestros durante fugas e invasões de residências, mobilizaram a opinião pública e diversas autoridades no intuito de desativação da unidade e da transferência dos detentos, conforme entrevistas concedidas à época.

A situação agravou-se em abril de 2012, quando a comunidade universitária, após invasão do campus por presidiários em fuga, deflagrou greve total (que perdurou por 6 meses) até que uma solução definitiva fosse aprovada.

O impasse gerado pelo conflito de ocupação espacial da região foi "solucionado" com a aprovação da desativação da unidade, construção do novo presídio fora da cidade e eventual transferência dos detentos. A desativação do Presídio Desembargador Luiz de Oliveira Souza foi efetivada no ano de 2013 e a edificação foi doada pelo governo do Estado à Universidade Federal de Alagoas através de assinatura de termo de cessão de uso em 11 de julho de 2014 (Araújo, 2014).

A transferência do estabelecimento para um novo edifício (Figura 10), localizado nos arredores da cidade de Craíbas (a cerca de $20 \mathrm{~km}$ de Arapiraca), inaugurado em 2013, aparentemente inicia novo e semelhante processo de ocupação nas suas imediações, com a presença de pequenos comércios em frente ao estabelecimento, assim como novas induções decorrentes dos fluxos de transporte público, abastecimento dos serviços básicos ao funcionamento da unidade, o que acaba beneficiando as comunidades circunvizinhas pelo fornecimento desses serviços, agora justificados pela segurança do estabelecimento penal (!). 


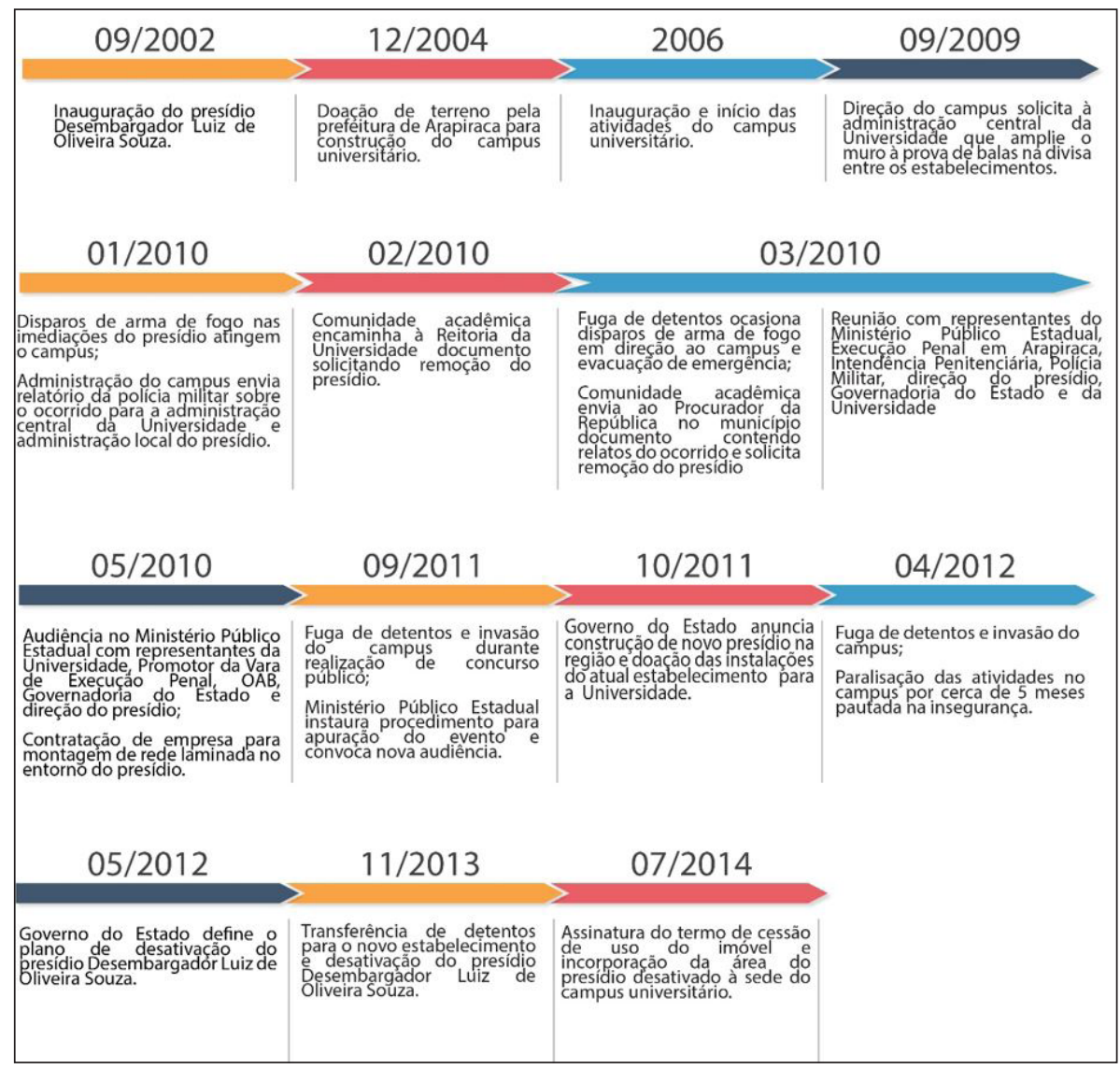

Figura 9 - Linha do tempo de acontecimentos Fonte: autores.

Quadro 1 - Lista de documentos consultados

\begin{tabular}{|c|c|}
\hline Documento & Data \\
\hline Lei 2374/2004 - doação do terreno da UFAL pela prefeitura & $\mathrm{dez} / 04$ \\
\hline Ofício 489/2009 da direção do campus à Superintendência de Infraestrutura da Universidade & set/09 \\
\hline Ofício 25/2010 da administração do campus ao diretor do presídio & jan/10 \\
\hline Relatório D34/2010 do $3^{\circ}$ Batalhão de Polícia Militar de Alagoas & jan/10 \\
\hline Cl 4/10 do administrador do campus ao diretor do campus & jan/10 \\
\hline Ofício 40/2010 da direção do campus à Reitoria da Universidade & $\mathrm{fev} / 10$ \\
\hline Ofício 39/2010 da direção do campus à Superintendência de Infraestrutura da Universidade & fev/10 \\
\hline Relatório de acontecimentos enviado pela comunidade acadêmica ao Procurador da República em Arapiraca & $\mathrm{mar} / 10$ \\
\hline Carta de envio do relatório da reunião de 11/3/2010 à Reitora da Universidade & $\mathrm{mar} / 10$ \\
\hline Convite da comissão da comunidade acadêmica à Reitoria da Universidade & $a b r / 10$ \\
\hline Convite da comissão da comunidade acadêmica ao Procurador da República de Arapiraca Samir Cabus Nachef Jr. & $a b r / 10$ \\
\hline Ata de audiência no MPE em 5/5/2010 & $\mathrm{mai} / 10$ \\
\hline Ofício n. 44/2010 do MPE ao Coronel Dario Cesar Barros Cavalcante & $\mathrm{mai} / 10$ \\
\hline Publicação no DOU do Estado de Alagoas de 17/5/2010 - p. 33 & mai/10 \\
\hline Portaria 10/2011 do MPE & set/11 \\
\hline
\end{tabular}

Fonte: autores. 


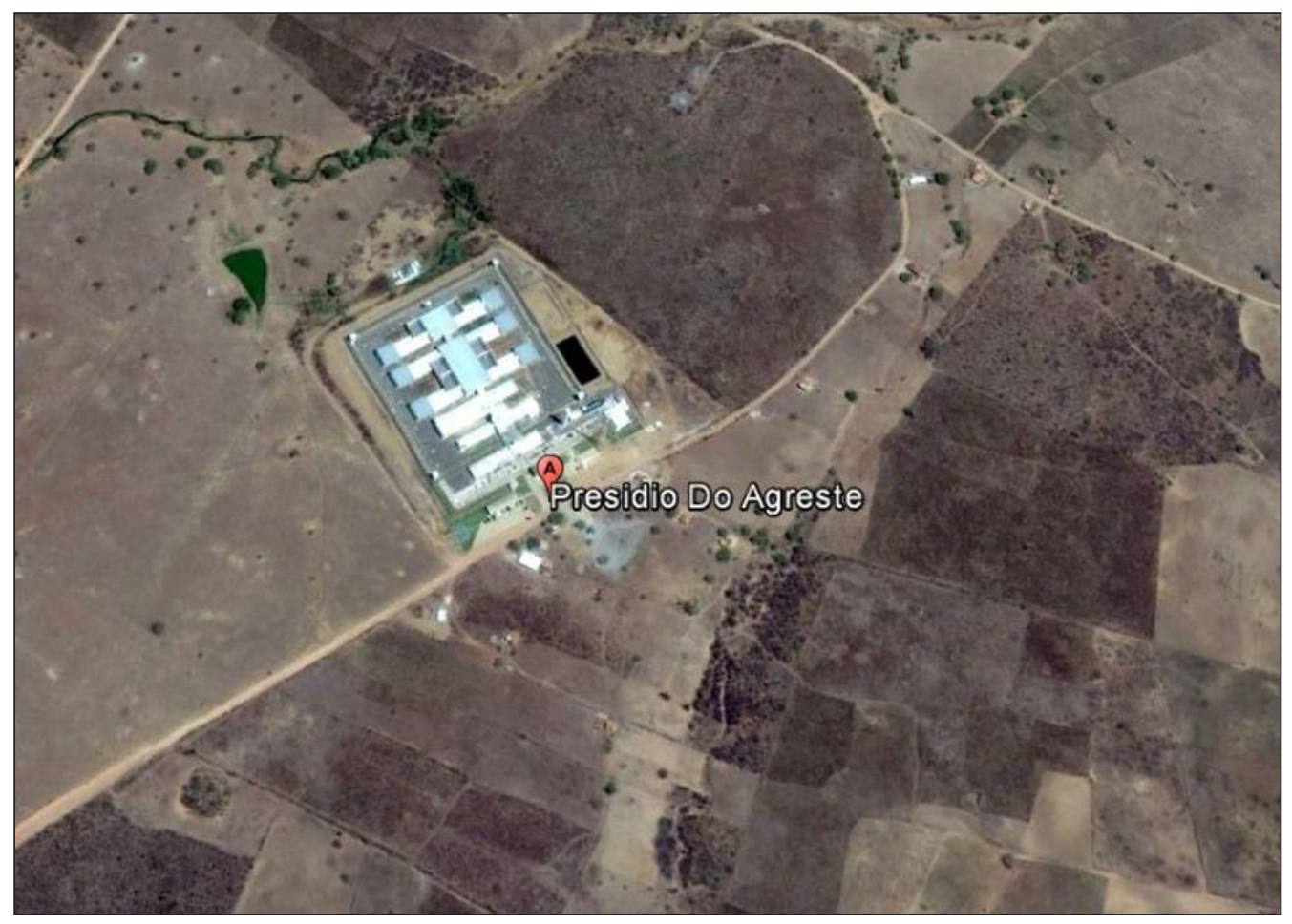

Figura 10 - Instalações da nova unidade penal

Fonte: Google Earth ${ }^{\circledast}$.

\section{A política urbana no contexto do problema}

Voltando-se para o papel da administração pública na resolução de conflitos como o descrito no estudo de caso de Arapiraca, depara-se com o papel fundamental de instrumentos como o Plano Diretor Municipal enquanto ferramenta de gestão e tomada de decisões.

Em seu artigo 48, item II, o Plano Diretor do Município de Arapiraca considera a cidade enquanto espaço de prática da cidadania e convívio social. Já em seu artigo 50, item I, o documento define como objetivos centrais da política de uso e ocupação do solo:

- tornar compatível a política urbana com a função social da propriedade;

- adequar a ocupação dos espaços tendo em vista a saúde, a segurança da população e os aspectos do patrimônio natural e cultural.

O mesmo documento ainda cita, em seu capítulo V, a existência de Estudo de Impacto de Vizinhança (EIV) e Relatório de Impacto de Vizinhança (RIV) como documentos necessários para obtenção de licenças ou autorizações de construção, ampliação ou funcionamento de estabelecimentos. 0 mesmo capítulo institui que tais documentos sejam executados de forma a contemplar os efeitos positivos e negativos do empreendimento ou atividade quanto à qualidade de vida da população residente na área e suas proximidades.

Ainda que o Plano Diretor Municipal de Arapiraca tenha sido aprovado após a construção de ambos os estabelecimentos (penitenciária e campus universitário), ele não apresenta em nenhum momento a inserção urbana ou, ainda, regulamentações e previsões de procedimentos para estabelecimentos relacionados à segurança pública.

Tal fato é claramente constatado ao se observar que no mapeamento de equipamentos urbanos apenas são considerados os estabelecimentos/áreas voltados à saúde, educação, cultura, esporte, lazer e alimentação (Figura 11). Além disso, as aplicações do EIV/RIV, por exemplo, ficam previstas apenas para estabelecimentos como: casas de diversões noturnas, clubes, salões de festas, posto de serviço com venda de combustível, depósito de gás liquefeito de petróleo, transportadoras, hospitais e clínicas médicas, locais com capacidade de estacionamento e motel (art.129 do Plano Diretor Municipal).

A não previsão de procedimentos técnicos nos documentos de planejamento e gestão urbana 


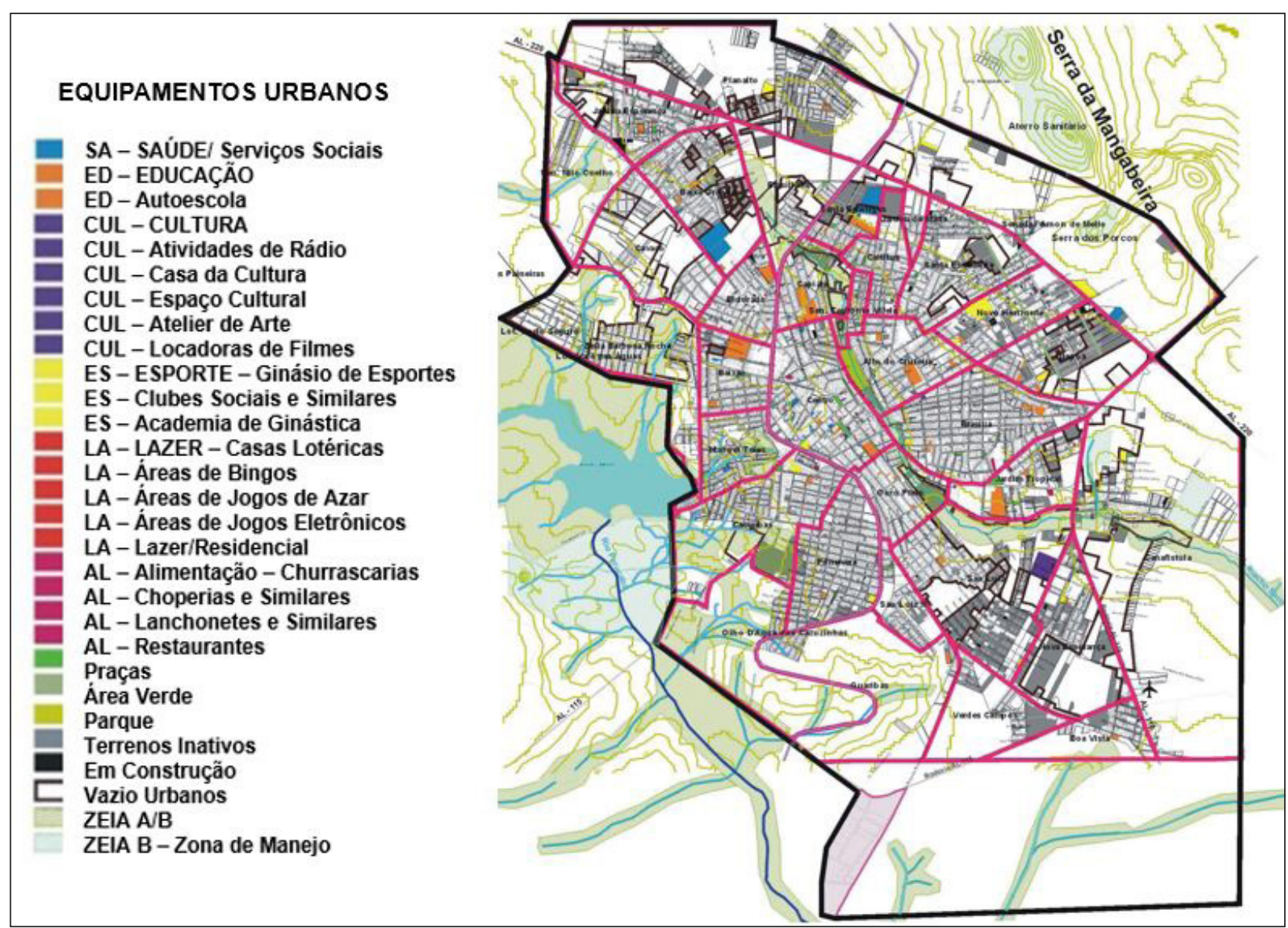

Figura 11 - Mapeamento de equipamentos urbanos

Fonte: Plano Diretor do Município de Arapiraca.

acaba tornando o posicionamento da administração pública, em situações como a descrita, num gesto de não política urbana para a adaptação das dinâmicas espaciais que consideram a complexidade de relações com um estabelecimento penal.

A partir do momento em que se opta por realocar um estabelecimento dessa natureza e não se aproveita a atmosfera dos acontecimentos para uma reflexão e melhoria das ferramentas de gestão urbana, o gestor municipal apenas se esquiva de um problema e a gestão continua despreparada para lidar com situações da mesma natureza.

0 mesmo pode ser posto para o recente caso do município de Manaus (Amazonas), em que a prefeitura estuda a possibilidade de criação de lei e alteração do Plano Diretor no sentido de proibir a construção de penitenciárias no meio urbano ao invés de desenvolver políticas públicas de gerenciamento do espaço em consonância com o ambiente que o cerca, ressaltando as dificuldades de a administração promover estudos e análises técnicas quando se trata de segurança pública.

\section{Considerações finais}

Intervir no espaço urbano, planejar e gerir bem os recursos públicos em todas as esferas da política pública é sempre um desafio, e, no que diz respeito à redução dos índices de violência urbana, a sua efetividade passa pela integração entre várias políticas públicas.

0 preso não só tem deveres a cumprir, como também é sujeito de direitos, que devem ser reconhecidos e amparados pelo Estado. 0 recluso não está fora do direito, pois se encontra numa relação jurídica com o Estado e, à exceção de direitos perdidos e limitados com sua condenação (liberdade, no caso dos reclusos), sua condição jurídica é a mesma de pessoas não condenadas, tais como o direito à vida, o direito à propriedade, o direito à família, o direito de 
orientar a educação dos filhos, os direitos sociais e o tratamento reeducativo, que é o direito fundamental, do qual derivam os demais.

Salienta-se que o espaço penal ou penitenciário se mantém na ilegalidade urbana quanto a sua função de inclusão social de cidadãos, margeando-o da cidade, excluído do contexto da função social da própria cidade, embora apresente regras quanto a sua função perante a mesma, do ponto de vista jurídico. Dessa forma, cumpre um papel urbano, mesmo configurado como espaço de banimento. A indiferença quanto ao espaço penal traz para a cidade alguns custos extras que poderiam, certamente, ser reduzidos se houvesse tal planejamento.

O equívoco persiste na interpretação dos estabelecimentos penais como espaços de isolamento. São desperdiçadas vidas humanas em idade produtiva, que se tornam parasitárias do poder público por ausência de políticas que visem a mudança de paradigmas. As idiossincrasias referentes ao objetivo da pena, à Lei de Execuções Penais e legislação municipal que regulamenta o uso do solo, por exemplo, nos remetem ao posicionamento conservador atual, o qual se apresenta diante da questão penitenciária. Como seria se os estabelecimentos fossem lucrativos ou, ao menos, autossustentáveis? Indubitavelmente, seria interesse da sociedade que os estabelecimentos fizessem parte da cidade, pois as empresas poderiam ter seus lucros, o Estado não estaria consumindo tanto da sua arrecadação, podendo investir em outras necessidades, os presos estariam perto de sua família e aprenderiam a "se comportar" dentro da sociedade. Dessa maneira, o estabelecimento penal conseguiria pagar pela terra que ocupasse dentro da escala de produção e da organização da cidade, como nos fala Ana Amélia da Silva. Obviamente, essa é uma solução simplista para tal situação, mas deveria, ao menos, ser debatida.

Essa pesquisa demonstra que é importante "agregar princípios de segurança ao planejamento urbano ou aprimoramento de espaços já construídos e integrar iniciativas espaciais e sociais para enfrentar o desafio coletivo de elevar a segurança nas cidades" (Gartner, 2008, p. 66).

Considerando que tudo que compõe a cidade deve correlacionar-se, incluindo-se, nesse contexto, os equipamentos urbanos de segurança pública, entende-se que não basta apenas implantar um equipamento urbano de segurança pública sem observar as necessidades e prioridades para a cidade. Um plano de segurança deverá prever os locais de implantação, os projetos executivos adequados, os materiais a serem utilizados e os cuidados relativos à sua manutenção e conservação. Assim, torna-se necessário que os planejadores, gestores, estudiosos e todos aqueles que têm ingerência sobre o fazer a cidade busquem levar em consideração os fatores que influenciam essa sustentabilidade.

Deve-se observar, portanto, num contexto global, o ambiente e a vida em sociedade, bem como garantir que a qualidade de vida atual e futura possa ser menos desigual, e, no mínimo, satisfazer as necessidades básicas da população, dentre elas, a questão da segurança pública.

\section{Referências}

Bibiano, B. (2012, 17 de setembro). No Estado mais violento do País, universidade federal é ameaçada por presídio. R7 Notícias. Recuperado em 17 de julho de 2015, de http://noticias.r7.com/educacao/noticias/no-estadomais-violento-do-pais-universidade-federal-e-ameacadapor-presidio-20120917.html

Brasil. (1940, 07 de dezembro). Decreto-Lei no 2.848 de 07 de dezembro de 1940. Brasília: Diário Oficial da União, p. 2391.

Brasil. (1984, 11 de julho). Decreto-Lei no 7.210 de 11 de julho de 1984. Brasília: Diário Oficial da União, p. 10227.

Brasil. (2001, 11 de julho). Decreto-Lei no 10.257 de 10 de julho de 2001. Brasília: Diário Oficial da União, seção 1, p. 1.

Carlos, A. F. A. (Org.). (1994). Os caminhos da reflexão sobre a cidade e o urbano. São Paulo: Edusp.

Cordeiro, S. (2013). 0 espaço penal e o direito à cidade como política urbana. In Anais do Encontro Nacional da ANPUR. Recife: ANPUR. Recuperado em 14 de abril de 2015, de http://unuhospedagem.com.br/revista/rbeur/ index.php/anais/article/viewFile/4662/4530

Cordeiro, S., \& Souza, F. A. M. (2004). A (I)legalidade do espaço penitenciário x o direito à cidade como política urbana. In Anais do $3^{\circ}$ Congresso Brasileiro de Direito Urbanístico. Recife: Instituto Brasileiro de Direito Urbanístico - IBDU.

Coutinho, L. (2010). Ainda há vida após o fumo. Revista Veja, 2180, 108. 
Foucault, M. (2012). Primeiras discussões, primeiros balbucios: a cidade é uma força produtiva ou de antiprodução? In: Foucault, M. Segurança, penalidade, prisão (M. B. Motta, organização e seleção de textos). Rio de Janeiro. Forense Universitária.

Gartner, A. (2008). Desenho do espaço público como ferramenta para a prevenção da violência. Revista Brasileira de Segurança Pública, 2(1). Edição 3.

Instituto Brasileiro de Geografia e Estatística - IBGE. (2014). Censo demográfico. Rio de Janeiro: IBGE. Recuperado em 14 de abril de 2015, de http://cidades.ibge.gov.br/painel/ historico.php

Montaner, J. M., \& Muxí, Z. (2013). Arquitetura e política: ensaios para mundo alternativos. Barcelona: Editorial Gustavo Gilli.

Núcleo de Estatística e Análise Criminal - NEAC. (2015). Boletim anual da estatística criminal. Maceió: SEDS. Recuperado em 16 de julho de 2015, de http://dados. al.gov.br/dataset/boletim-criminal

Organização das Nações Unidas - ONU. (2000). Programa das Nações Unidas para o desenvolvimento - PNUD: perfil municipal - Arapiraca. Recuperado em 24 de março de 2017, de: http:// http://dados.al.gov.br/dataset/43ba0374-afb246f8-92f3-ed5f6fa45587/resource/0a745ff0-f4a0-4308891e-8a42d83d3bf1/download/municipalarapiraca2010.pdf
Ricardo, C. M., Caruso, H. G. C. (2007). Segurança pública: um desafio para os municípios brasileiros. Revista Brasileira de Segurança Pública, 1(1), 102-119.

Secretaria de Estado da Defesa Social - SEDS. (2009). Plano estadual de segurança pública. Maceió: SEDS. Recuperado em 02 de agosto de 2013, de http://www.defesasocial. al.gov.br

Soares, L. E. (2006). Segurança pública: presente e futuro. Estudos Avançados, 20(56), 91-106. http://dx.doi. org/10.1590/S0103-40142006000100008.

Souza, J. C. O. (2009). Reestruturação urbana e interações espaciais em cidades médias: o exemplo de Arapiraca, Alagoas. Geografia em Questão, 01, 107-117.

Waiselfisz, J. J. (2015). Mapa da Violência 2015: homicídios de mulheres no Brasil. Brasília: All Type Assessoria Editorial Ltda. Recuperado em 24 de março de 2017, de: http://www. mapadaviolencia.org.br/pdf2015/MapaViolencia_2015_ mulheres.pdf

Waiselfisz, J. J. (2016). Mapa da violência 2016: homicídios por armas de fogo no Brasil. Recuperado em 24 de março de 2017, de: http://flacso.org.br/files/2016/08/ Mapa2016_armas_web.pdf

Recebido: Out. 12, 2016

Aprovado: Set. 16, 2017 